\title{
Diagnostic value of history and physical examination in patients suspected of lumbosacral nerve root compression
}

\author{
P C A J Vroomen, M C T F M de Krom, J T Wilmink, A D M Kester, J A Knottnerus
}

See end of article for authors' affiliations

\section{Correspondence to:} Dr Patrick C A J Vroomen Department of Neurology, Maastricht University

Hospital, P Debyelaan 25, PO box 5800, 6202 AZ Maastricht, Netherlands; pvr@sneu.azm.nl

Received 10 April 2000 In revised form 7 August 2001

Accepted

22 January 2002
Objective: To evaluate patient characteristics, symptoms, and examination findings in the clinical diagnosis of lumbosacral nerve root compression causing sciatica.

Methods: The study involved 274 patients with pain radiating into the leg. All had a standardised clinical assessment and magnetic resonance (MR) imaging. The associations between patient characteristics, clinical findings, and lumbosacral nerve root compression on MR imaging were analysed.

Results: Nerve root compression was associated with three patient characteristics, three symptoms, and four physical examination findings (paresis, absence of tendon reflexes, a positive straight leg raising test, and increased finger-floor distance). Multivariate analysis, analysing the independent diagnostic value of the tests, showed that nerve root compression was predicted by two patient characteristics, four symptoms, and two signs (increased finger-floor distance and paresis). The straight leg raise test was not predictive. The area under the curve of the receiver-operating characteristic was 0.80 for the history items. It increased to 0.83 when the physical examination items were added.

Conclusions: Various clinical findings were found to be associated with nerve root compression on MR imaging. While this set of findings agrees well with those commonly used in daily practice, the tests tended to have lower sensitivity and specificity than previously reported. Stepwise multivariate analysis showed that most of the diagnostic information revealed by physical examination findings had already been revealed by the history items.
$\mathrm{D}$ isc herniation often does not cause symptoms. ${ }^{1}$ On the other hand, it may cause sciatica by compressing the nerve roots. Diagnostic procedures such as magnetic resonance (MR) imaging help to establish disc herniation as the anatomical basis for sciatica. Several treatments, especially discectomy, have been advocated for patients with sciatica, but are indicated only if nerve root compression is considered to be the cause. ${ }^{2-4}$ Therefore, an accurate initial clinical diagnosis of nerve root compression is highly desirable. ${ }^{56}$

In one systematic review of the value of history and physical examination in radicular syndromes it was concluded that none of the tests used had a high sensitivity or specificity. ${ }^{7}$ Unfortunately, various symptoms and some commonly assessed clinical signs were not reviewed in that study. It was concluded in two other reviews ${ }^{89}$ that the diagnostic value of many signs and symptoms had not been thoroughly investigated.

The most common methodological drawbacks in previous studies have been the choice of a suboptimal gold standard, selection bias, and univariate analysis. . In many studies disc herniation rather than nerve root compression was used as the gold standard. However, disc herniation need not result in nerve root compression and has been found to be asymptomatic in many subjects. ${ }^{10}$ Also, in several previous studies the history and physical examination findings probably affected the selection of the patients for the study. ${ }^{9}$ This so called "sequential ordering bias" occurs when patients with positive findings are more likely to be selected for study than patients with negative findings. ${ }^{11-14}$ Finally, previous analytical methods have used univariate analysis; multivariate analysis, however, allows one to assess the contribution of separate clinical findings to the overall diagnosis, taking into account the high degree of correlation between clinical findings.

With these factors in mind, we undertook a cross sectional study examining the value of history and physical examina- tion in the diagnosis of nerve root compression. We studied patients presenting to a primary care physician with a new episode of pain radiating into the leg, and we used MR imaging to establish the presence of nerve root compression.

\section{METHODS}

\section{Study population}

Fifty general practitioners in Maastricht and surrounding villages referred patients with a new episode of pain radiating into the leg below the gluteal fold to the neurology department of the Maastricht University Hospital. In this study we only included patients with pain sufficiently severe to justify further action (defined as pain that might justify bed rest for 14 days, because part of the study population was involved in a trial of bed rest ${ }^{15}$ ). Exclusion criteria were previous spinal surgery, pregnancy, severe comorbidity, or contraindication to MR imaging (metal containing prostheses, pacemakers).

\section{Investigations}

Eligible patients gave their written informed consent for the study within two days of the first general practitioner consultation. Clinical findings were then established in a standardised fashion based on good clinical practice, standard textbook sections, and published reports. The methods and interobserver consistency of the history and physical examination have been reported elsewhere. ${ }^{16}$

The gold standard in all patients was MR imaging of the lumbar spine within 24 hours after the clinical examination. ${ }^{17}$ This was performed using a $0.5 \mathrm{~T}$ system according to the following scanning protocol: first, sagittal and transverse $\mathrm{T}_{1}$ weighted sequences (TR/TE 400-600/20 ms) with 4 and $5 \mathrm{~mm}$ slice thickness, respectively; and second, a sagittal dual echo proton density and $\mathrm{T}_{2}$ weighted sequence (fast spin echo 


\begin{tabular}{|c|c|c|c|}
\hline Characteristic & $M R I+(n=152)$ & MRI- $(n=122)$ & Odds ratio $(95 \% \mathrm{Cl})$ \\
\hline \multicolumn{4}{|c|}{ Age (years) (mean (SD), 46 (12) years) } \\
\hline $16-40$ & 43 & 48 & \\
\hline $41-50$ & 50 & 44 & $1.3(0.7$ to 2.3$)$ \\
\hline $51-81$ & 59 & 30 & $2.2(1.2$ to 4.0$)$ \\
\hline Male sex & 67 & 72 & $1.8(1.1$ to 3.0$)$ \\
\hline \multicolumn{4}{|c|}{ Duration of disease (median 19 days) } \\
\hline 14 days or less & 70 & 55 & \\
\hline $15-30$ days & 41 & 19 & 1.7 (0.9 to 3.2 ) \\
\hline$>30$ days & 41 & 48 & $0.7(0.4$ to 1.2$)$ \\
\hline Living alone & 29 & 19 & $1.3(0.7$ to 2.4$)$ \\
\hline High education level & 45 & 25 & $1.6(0.9$ to 2.9$)$ \\
\hline \multicolumn{4}{|l|}{ Job type } \\
\hline No job & 66 & 43 & \\
\hline Cognitive & 42 & 26 & $1.1(0.6$ to 2.0$)$ \\
\hline Standing/walking/lifting & 28 & 36 & 0.5 (0.3 to 0.95$)$ \\
\hline Physically demanding & 16 & 17 & $0.6(0.3$ to 1.3$)$ \\
\hline Any comorbidity & 64 & 44 & $1.3(0.8$ to 2.1$)$ \\
\hline Smoking & 65 & 63 & $0.7(0.4$ to 1.1$)$ \\
\hline Sports activities & 67 & 51 & $1.1(0.7$ to 2.2$)$ \\
\hline Exercised back/abd muscles & 60 & 54 & $0.8(0.5$ to 1.3$)$ \\
\hline Family history sciatica & 51 & 38 & $1.1(0.7$ to 1.9$)$ \\
\hline Quetelet index (mean (SD)) & $25.5(5.1)$ & $25.6(4.0)$ & $p=0.79$ \\
\hline
\end{tabular}

TR/TE 4500/25-150 ms) with $5 \mathrm{~mm}$ slice thickness. We also carried out MR radiculography, consisting of two heavily T2 weighted fast spin echo sequences (TR/TE 6000/450 ms) with $4 \mathrm{~mm}$ slice thickness, oriented parallel to the emerging L5 root, about $20^{\circ}$ left and right oblique to the coronal plane, reformatted with a maximum intensity projection protocol. ${ }^{18}$

A standardised assessment of all MR imaging studies was done by a neuroradiologist (JW) experienced in spinal magnetic resonance imaging. The assessment focused on the presence or absence of nerve root (sleeve) compression. Criteria used for grading included the presence of a protruding annulus or extruded nucleus material, or lateral recess narrowing on standard MR imaging, and flattening and compression of the ventrolateral border of the dural sac or emerging nerve root sleeve, with obliteration of the surrounding epidural fat. In the MR radiculography images, positive criteria included dural impressions, kinking, and swelling of the intradural nerve root and cut off of the root sleeve filling.
The clinical investigator was unaware of the MR findings, while the neuroradiologist was unaware of the clinical findings.

\section{Statistical analysis}

For the analysis the statistical package for the social sciences (SPSS) was used. A bivariate analysis was based on $2 \times 2$ tables relating history and physical examination items to nerve root compression on MR imaging. Sensitivity, specificity, and likelihood ratios for positive and negative test results (LR+ and LR-) were calculated, as well as the diagnostic odds ratio $(\mathrm{DOR}$, with DOR $=\mathrm{LR}+/ \mathrm{LR}-) .{ }^{19}{ }^{20}$ The statistical significance of the association was assessed using Pearson's $\chi^{2}$ statistic.

In a backward stepwise logistic regression analysis, ${ }^{21}{ }^{22}$ the likelihood ratio test was used for each step at a significance level of 0.05. First, a set of general patient characteristics (all variables in table 1) was modelled, leading to model A.

Table 2 Diagnostic accuracy of the history $(n=274)$

\begin{tabular}{|c|c|c|c|}
\hline Characteristic & $M R I+(n=152)$ & MRI- $(n=122)$ & Odds ratio $(95 \% \mathrm{Cl})$ \\
\hline Pain worse in leg than in back & 125 & 56 & 5.5 (3.2 to 9.4$)$ \\
\hline Typically dermatomal distribution & 136 & 84 & 3.8 (2.0 to 7.3$)$ \\
\hline $\begin{array}{l}\text { Pain worse on coughing/sneezing/ } \\
\text { straining }\end{array}$ & 76 & 40 & 2.1 (1.3 to 3.4$)$ \\
\hline Dermatomal cold sensations in leg & 47 & 24 & 1.8 (1.0 to 3.2$)$ \\
\hline More pain on sitting & 82 & 69 & $0.9(0.6$ to 1.5$)$ \\
\hline Less pain standing or walking & 31 & 26 & $0.9(0.5$ to 1.7$)$ \\
\hline Less pain on lying down & 91 & 69 & $1.1(0.7$ to 1.9$)$ \\
\hline Sudden onset & 60 & 51 & 0.9 (0.6 to 1.5$)$ \\
\hline Paroxysmal pattern & 67 & 47 & $1.3(0.8$ to 2.0$)$ \\
\hline Pain worse at night & 47 & 42 & $0.9(0.5$ to 1.4$)$ \\
\hline With known cause & 38 & 37 & $0.8(0.5$ to 1.3$)$ \\
\hline Subjective muscle weakness & 41 & 46 & $0.6(0.4$ to 1.0$)$ \\
\hline Subjective sensory loss & 60 & 51 & $0.9(0.6$ to 1.5$)$ \\
\hline Dermatomal paraesthesiae & 78 & 72 & $0.7(0.5$ to 1.2$)$ \\
\hline Previous back pain episodes & 113 & 85 & $1.3(0.7$ to 2.1$)$ \\
\hline Previous sciatica & 55 & 52 & 0.8 (0.5 to 1.2$)$ \\
\hline $\begin{array}{l}\text { History indicating root compression } \\
\text { according to investigator }\end{array}$ & 118 & 64 & 3.1 (1.9 to 5.3$)$ \\
\hline
\end{tabular}

Values in bold indicate significant effect.

$\mathrm{Cl}$, confidence interval; $\mathrm{MRI}+/-$, magnetic resonance imaging positive or negative. 
Table 3 Diagnostic accuracy of the physical examination $(n=274)$

\begin{tabular}{|c|c|c|c|}
\hline Characteristic & $M R I+(n=152)$ & MRI- $(n=122)$ & Odds ratio $(95 \% \mathrm{Cl})$ \\
\hline Paresis & 41 & 8 & 5.2 (2.4 to 11.7$)$ \\
\hline Finger-floor distance $\geqslant 25 \mathrm{~cm}$ & 68 & 32 & 2.4 (1.4 to 4.0$)$ \\
\hline Absence of ankle/knee tendon reflex & 22 & 8 & $2.4(1.0$ to 5.6$)$ \\
\hline Positive SLR & 97 & 53 & 2.3 (1.4 to 3.7$)$ \\
\hline \multicolumn{4}{|l|}{ Sensory loss } \\
\hline Hypesthesia & 43 & 42 & $0.8(0.5$ to 1.3$)$ \\
\hline Hypalgesia & 26 & 19 & $1.2(0.6$ to 2.1$)$ \\
\hline $\begin{array}{l}\text { History and examination indicating root } \\
\text { compression according to investigator }\end{array}$ & 123 & 59 & 4.5 (2.6 to 7.8$)$ \\
\hline
\end{tabular}

Values in bold indicate significant effect.

$\mathrm{Cl}$, confidence interval; $\mathrm{MRI}+/-$, magnetic resonance imaging positive or negative; SLR, straight leg raise.

Second, a set of history items (all variables in table 2) was modelled (model B), also including the variables in model A that were significantly predictive. Third, all physical examination findings in table 3 and the significant predictors of model $\mathrm{B}$ were modelled into the final reduced model C (presented in table 4).

The neuroradiologist assessed 60 scans twice to allow calculation of a $\kappa$ value for intraobserver variability. ${ }^{21}$

The probability of nerve root compression on MR imaging predicted by the various reduced models was calculated for each patient. Subsequently, to evaluate the predictive power of each model, receiver-operating characteristic (ROC) curves were plotted, displaying the sensitivity $v(1-$ specificity) for each cut off point of predicted posterior probability. ${ }^{23}{ }^{24}$ The areas under the ROC curves were calculated. The probability cut off with the maximum expected gain was determined as the point with the highest sum of sensitivity and specificity. ${ }^{25}$ As a reference, the sensitivity and specificity of the observer's summary statement on the presence of nerve root compression are shown (at the bottom of tables 2 and 3 ) .

\section{Ethics}

The procedures of this study were in accordance with the ethical standards of the revised Helsinki declaration of 1983 and were approved by the Maastricht University Hospital ethics committee.

Table 4 Predictors of nerve root compression on magnetic resonance imaging: results of multiple logistic regression analysis $(n=274)$

\begin{tabular}{|c|c|c|}
\hline Test & $\begin{array}{l}\text { Adjusted } \\
\text { diagnostic OR }\end{array}$ & $95 \% \mathrm{Cl}$ \\
\hline \multicolumn{3}{|l|}{ History } \\
\hline \multicolumn{3}{|l|}{ Age (years) } \\
\hline $41-50 \times 16-40$ & 1.8 & 1.3 to 2.6 \\
\hline $51-81 \vee 16-40$ & 2.8 & 1.9 to 4.2 \\
\hline \multicolumn{3}{|l|}{ Duration of disease (days) } \\
\hline $15-30 v<15$ & 2.2 & 1.5 to 3.3 \\
\hline$>30 v<15$ & 0.8 & 0.6 to 1.1 \\
\hline Paroxysmal pain & 1.8 & 1.3 to 2.5 \\
\hline Pain worse in leg than in back & 4.5 & 3.3 to 6.2 \\
\hline Typical dermatomal distribution & 3.2 & 2.2 to 4.7 \\
\hline $\begin{array}{l}\text { Pain worse on } \\
\text { coughing/sneezing/straining }\end{array}$ & 2.0 & 1.4 to 2.7 \\
\hline \multicolumn{3}{|l|}{$\begin{array}{l}\text { Physical examination } \\
\text { Finger-floor distance }(\mathrm{cm})\end{array}$} \\
\hline $5-24 \vee 0-4$ & 1.1 & 0.7 to 1.6 \\
\hline$>25 \vee 0-4$ & 2.8 & 1.9 to 4.3 \\
\hline Missing $\vee 0-4$ & 1.0 & 0.4 to 2.1 \\
\hline Paresis & 5.2 & 3.3 to 11.6 \\
\hline Intercept & -3.511 & \\
\hline
\end{tabular}

\section{RESULTS}

In all, 338 patients were referred for the diagnostic study. Sixty four were excluded ( 35 because of insufficient pain and 29 because of previous spinal surgery or contraindications to MR imaging). Thus the investigations were carried out in 274 patients. The intraobserver consistency of the MR imaging diagnosis of nerve root compression was high ( $\kappa$ value 0.83 ).

Table 1 shows the most important patient characteristics. Root compression was found on $56 \%$ of the MR imaging studies. The pain radiating into the leg was clinically diagnosed as sciatica in $67 \%$ of patients, while other diagnoses included coxarthrosis, spondylolisthesis, regional neoplastic growth, peripheral neuropathy, and pain of tendomyogenous or other origin. The sample included sciatica patients both with and without various degrees of neurological deficit. Two patients suffered from urinary incontinence and saddle anaesthesia.

In the univariate analysis, there was an association between nerve root compression on MR imaging and three patient

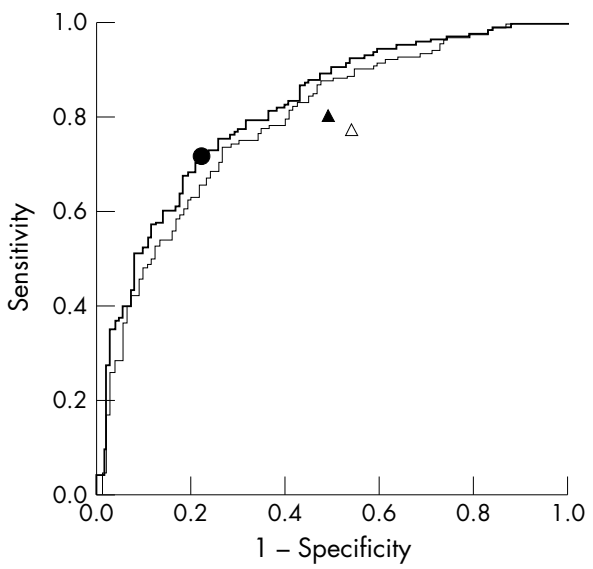

Figure 1 Upper curve: diagnostic value of history and physical examination (variables in table 4 ; area under the curve $=0.83$ ). Lower curve: diagnostic value of history (area under the curve $=0.80$ ). - Maximum diagnostic gain of model according to Connell and Koepsell. ${ }^{25} \triangle$ Sensitivity and $1-$ specificity for the observer's diagnosis after history. $\Delta$ Sensitivity and 1 - specificity for the observer's diagnosis after history and physical examination. A physician makes a diagnosis of nerve root compression when he feels that the clinical findings indicate disease with a high enough probability. The latter is the physician's intrinsic cut off probability of disease. For example, the intrinsic cut off probability for the observer is shown by the black triangle in the figure. The logistic models allows an estimation of diagnostic properties for all possible probability cut off points. Plotting these properties results in the receiveroperating characteristic. The area under the curve represents the overall diagnostic value of the model regardless of cut off probability. Maximum diagnostic gain might be estimated as the point in the upper left hand corner or as the highest sum of sensitivity and specificity as proposed by Connell and Koepsell. ${ }^{192}$ 
characteristics: age, sex, and having a job with a predominance of standing, walking, or lifting activities (table 1). MR imaging was also associated with three symptoms: typical dermatomal pain, coldness in the leg, and increased pain on coughing, sneezing, or straining (table 2). Four physical examination items were discriminative: paresis, a finger-floor distance of more than $25 \mathrm{~cm}$, absence of knee or ankle tendon reflex, and a positive straight leg raise test (table 3 ).

However, in diagnosing nerve root compression clinical findings are not considered separately but in combination. This is reflected in multiple logistic regression models, which allow calculation of the independent predictive value of patient characteristics and clinical findings and predict the probability of nerve root compression. Table 4 shows that two general patient characteristics (age and duration of disease), four symptoms from the history, and two signs from the physical examination were independent predictors of nerve root compression. The straight leg raise test was not a significant predictor, while an increased finger-floor distance and paresis were significant predictors.

The area under the curve of the ROC for the model using history findings alone was 0.80 . This increased to 0.83 when the examination findings were added (fig 1). Maximum predictive gain of the model occurred at a predicted probability value of 0.625 with a sensitivity and specificity of $72 \%$ and $80 \%$, respectively.

\section{DISCUSSION}

In our 274 primary care patients with leg pain, three patient characteristics, three symptoms, and four signs were associated with nerve root compression on MR imaging. However, the sensitivity and specificity values we found in this study were lower than previously reported. ${ }^{7}$ Different study populations and designs may explain this. ${ }^{13}$

Positive clinical findings were not the reason for referral in our study and therefore we have avoided the verification bias $^{25}{ }^{26}$ and spectrum bias ${ }^{27}$ of previous studies. There are also indirect clues that the participating patients were indeed an unbiased primary care population. For example, both sexes were equally represented, while previous secondary care patient series have included nearly twice as many men as women. Also, neurological deficits were far less common in our patient sample than in previous series. ${ }^{9}$ To avoid including asymptomatic or minor conditions, we accepted only those patients who had severe pain radiating into the leg. We felt that a clinical diagnosis of nerve root compression in patients with no leg pain was probably rare and in any case should not lead to discectomy.

MR imaging was used as the state of the art procedure to demonstrate nerve root compression. ${ }^{17}{ }^{28-30}$ Sensitivity and specificity values of MR imaging in the diagnosis of disc herniation range from $71 \%$ to $100 \%$ and from $50 \%$ to $86 \%$, respectively. ${ }^{1731}{ }^{32}$ Several investigators have reported disc herniation in asymptomatic subjects using MR imaging, ${ }^{133} \mathrm{com}$ puted tomography, ${ }^{34}$ and caudography. ${ }^{35}$ However, none of these related the disc herniation to the presence of nerve root compression. Some false negative diagnoses may be explained by changes in the pathological anatomy of the nerve root with posture and over time. ${ }^{36}$ The additional value of MR radiculography has yet to be unequivocally demonstrated. ${ }^{18}$

The only history item that could be compared with a previous report was the typical dermatomal pain distribution. This had a $90 \%$ sensitivity in our study, compared with $99 \%$ sensitivity in a study by Kerr and colleagues. ${ }^{37}$ Strikingly, subjective muscle weakness and sensory loss actually diminished the likelihood of nerve root compression. These findings are at variance with current opinion and with our previous beliefs. The selection bias in previous studies may have affected our understanding of the true relation of these complaints to nerve root compression. It is possible that subjective weakness and sensory loss have no neurological basis in most patients.

Table 3 shows that four physical examination items were related to nerve root compression, and that even before the physical examination, the a priori likelihood of disease is altered by the history. Rather than considering only one or two tests, one should use history and physical examination as two batteries of tests, and interpret the items in each battery simultaneously. The independent and simultaneous contributions of tests to the diagnostic work up of the sciatica patient have not been studied previously. Table 4 and the ROC curve in fig 1 indicate that, after the history has been taken, few signs in the physical examination contribute to a more accurate diagnosis. Typically, a dermatomal distribution of pain, an increase in pain on coughing, sneezing, or straining, paroxysmal pain, and predominant leg pain are indicators of nerve root compression. This is in agreement with clinical experience. The predictive value of paresis also accords with general beliefs. ${ }^{8}$ A surprising predictor was an increased finger-floor distance. The action of bending over to touch the floor with the fingers not only stretches the nerve roots and the sciatic nerve but also cancels the lordosis of the lumbosacral spine; the latter action may accentuate the mechanical effect of the disc herniation on the nerve root. We were struck by the fact that the straight leg raise test was not a predictor of root compression. This test may indicate nerve root tension or irritation, but not necessarily nerve root compression.

\section{Conclusions}

The main component in the diagnosis of sciatica caused by disc herniation is the history. Few physical signs add useful additional information or result in alteration of a diagnosis made on the basis of the history.

\section{Authors' affiliations}

P C A J Vroomen, M C T F M de Krom, Department of Neurology, Maastricht University Hospital, Maastricht, The Netherlands

J T Wilmink, Department of Diagnostic Radiology, Division of Neuroradiology, Maastricht University Hospital

A D M Kester, Department of Methodology and Statistics, Maastricht University

J Knotterus, Department of General Practice, Maastricht University

\section{REFERENCES}

1 Jensen MC, Brant-Zawadzki MN, Obuchowski N, et al. Magnetic resonance imaging of the lumbar spine in people without back pain. $N$ Engl J Med 1994:331:69-73.

2 Mixter WJ, Barr JS. Rupture of the intervertebral disc with involvement of the spinal canal. N Engl J Med 1934;21 1:210-15.

3 Weber H. Lumbar disc herniation; a controlled, prospective study with ten years of observation. Spine 1983;8:131-40.

4 Hoffman RM, Wheeler KJ, Deyo RA. Surgery for herniated discs: a literature synthesis. J Gen Intern Med 1993;8:487-96.

5 Knutsson B. Comparative value of electromyographic, myelographic and clinical-neurological examinations in diagnosis of lumbar root compression syndrome. Acta Orthop Scand Suppl 1961;49:1-134.

6 Kosteljanetz M, Espersen JO, Halaburt H, et al. Predictive value of clinical and surgical findings in patients with lumbago-sciatica a prospective study (part I). Acta Neurochir 1984;73:67-76.

7 Hoogen HJMM, Koes BW, van Eijck JTM, et al. On the accuracy of history, physical examination and erythrocyte sedimentation rate in diagnosing low-back pain in general practice. Spine 1995;20:318-27.

8 Andersson GBJ, Deyo RA. History and physical examination in patients with herniated lumbar discs. Spine 1996;21:10-18S.

9 Vroomen PCAJ, de Krom MCTFM, Knottnerus JA. Diagnostic value of history and physical examination in patients with sciatica due to disc herniation; a systematic review. J Neurol 1999;246:899-906.

10 Andersson GB, Weinstein JN. Disc herniation [editorial]. Spine 1996;21:1S.

11 Feinstein AR. Clinical epidemiology: the architecture of clinical research. Philadelphia: WB Saunders, 1985.

12 Lachs MS, Nachamkin I, Edelstein PH, et al. Spectrum bias in the evaluation of diagnostic tests: lessons from the rapid dipstick test for urinary tract infection. Ann Intern Med 1992;117:135-40.

13 Knottnerus JA. The effects of disease verification and referral on the relationship between symptoms and disease. Med Decis Making 1987;7:139-48. 
14 Knottnerus JA, Leffers $P$. The influence of referral patterns on the characteristics of diagnostic tests. J Clin Epidemiol 1992;45: 1 143-54.

15 Vroomen PCAJ, Krom MCTFM, Wilmink JT, et al. Lack of effectiveness of bed rest for sciatica. N Engl J Med 1999;340:418-23.

16 Vroomen PCAJ, de Krom MCTFM, Knottnerus JA. The consistency of the history and the physical examination in the patient suspected of sciatica. Spine 2000;25:91-6.

17 Jackson RP, Cain J, Jacobs RR, et al. The neuroradiographic diagnosis of lumbar herniated nucleus pulposus: II. A comparison of computed tomography (CT), myelography, CT-myelography, and magnetic resonance imaging. Spine 1989;14:1362-7.

18 Hofman PAM, Wilmink JT. Optimising the image of the intradural nerve root: the value of MR radiculography. Neuroradiology 1996;38:654-7

19 Sackett DL, Haynes RB, Guyatt GH, et al. Clinical epidemiology. A basic science for clinical medicine. Boston: Little, Brown and Co, 1991:439.

20 Knottnerus JA, Volovics A. Medische statistiek en onderzoek in de huisartsgeneeskunde. NHG-Publikaties, vol 4. Utrecht: Nederlands Huisartsen Genootschap, 1990.

21 Altman DG. Practical statistics for medical research. London: Chapman and Hall, 1996.

22 Kleinbaum DG. Logistic regression: a self-learning text. In: Dietz K, Krickeberg K, Singer B, eds. Statistics in the health sciences. New York: Springer, 1994:282.

23 Metz CE. Basic principles of ROC analysis. Semin Nucl Med 1978;8:283-98.

24 Hanley JA. Receiver operating characteristic (ROC) methodology. Crit Rev Diagn Imaging 1989;29:307-35.

25 Connell FA, Koepsell TD. Measures of gain in certainty from a diagnostic test. Am J Epidem 1985;121:744-53.

26 Bernelot Moens HJ, Hirschberg AJ, Claessens AA. Data-source effects on the sensitivities and specificities of clinical features in the diagnosis of rheumatoid arthritis: the relevance of multiple sources of knowledge for a decision-support system. Med Decis Making 1992;12:250-8.

27 Ransohoff DF, Feinstein AR. Problems of spectrum and bias in evaluating the efficacy of diagnostic tests. N Engl J Med 1978;299:926-30.

28 Ellenberger C. MR imaging of the low back syndrome. Neurology 1994;44:594-600.

29 Deyo RA. Magnetic resonance imaging of the lumbar spine; terrific test or tar baby? N Engl J Med 1994;331:115-16.

30 Herzog RJ. The radiologic assessment for a lumbar disc herniation. Spine 1996;21:19-38S

31 Bischoff RJ, Rodriguez RP, Gupta K, et al. A comparison of computed tomography-myelography, magnetic resonance imaging, and myelography in the diagnosis of herniated nucleus pulposus and spinal stenosis. J Spinal Disord 1993;6:289-95.

32 Szypryt ET, Twining P, Wilde GP, et al. Diagnosis of lumbar disc protrusion. J Bone Joint Surg Br 1988;70:717-22.

33 Boden SD, Davis DO, Dina TS, et al. Abnormal magnetic-resonance scans of the lumbar spine in asymptomatic subjects. A prospective investigation. J Bone Joint Surg Am 1990;72:403-8.

34 Didry $C$, Lopez $P$, Baixas $P$, et al. Lumbar disk herniation with no surgical treatment. Clinical and x-ray computed tomographic follow-up study [in French]. Presse Med 1991;20:299-302.

35 Hitselberger WE, Witten RM. Abnormal myelograms in asymptomatic patients. J Neurosurg 1968;28:204-6.

36 Bozzao A, Gallucci M, Masciocchi C, et al. Lumbar disk herniation: MR imaging assessment of natural history in patients treated without surgery. Radiology 1992;185:135-41.

37 Kerr RSC, Cadoux-Hudson TA, Adams CBT. The value of accurate clinical assessment in the surgical management of the lumbar disc protrusion. J Neurol Neurosurg Psychiatry 1988;51:169-73. 